\title{
Separate development for science
}

Ziauddin Sardar, an information consultant at the King Abdul Aziz University, Jeddah, Saudi Arabia, argues for scientific independence for developing countries.

NARENDRA Singh's comments (9 March, page 112) on Michael J. Moravcsik's plea for "the voice of science of the Third World" (24 November, page 288) are a good illustration of the guif between the concerned and aware scientists of the developed and developing countries. Moravcsik is concerned with "scientific development" (which sounds a little omniscient), "foreign students", "scientific communication channels" and "self-image"; Singh is concerned with "politico-economic content" of science and technology, "self-reliance" and "selfsufficiency". Moravcsik is optimistic about the forthcoming United Nations Conference on Science and Technology for Development (UNCSTD); Singh is lukewarm.

I agree with much of what Singh has to say, although I would argue strongly for 'isolation'. By isolation I mean the need for the developing countries to drop out of the "science development" race propagated by Moravcsik and others.

Singh's entire approach to UNCSTD is conditioned by a realisation that is slowly taking root in the scientific and technological institutions of many developing countries: there is something inherent in science and technology as it is practised in the West that will never allow the developing countries to stand on their own feet. Furthermore, this "something" has an ideological character; and it is certainly too deeply entrenched to be weeded out by a single UN conference.

After all, one may ask, what is so special about UNCSTD? The developing countries have the experience of four UNCTAD meetings to learn from. On all four occasions the developed world categorically refused to see the point of view of the developing countries. The UNC'TAD meetings were concerned about economic injustice; the UNCSTD is concerned with the instruments that helped the creation of the injustice in the first place, and maintains the status quo.

There are strong signs that UNCSTD will meet the same fate as UNCTAD. The pre-organisation fiasco, the multi-national industrial lobby (which holds the monopoly of modern science and technology) persuading and forcing the US policy towards preserving their proprietary rights, the exclusion of any discussion of appropriate technologies per se, the emergence of 'north-south dialogue' - all indicate this direction. The stage is set not for a dialogue based on mutual self-respect, geared towards achieving positive results, but for a confrontation.

While the developing countries are forced into it, they do not desire a confrontation. On the ideological plane, they want a basic minimum standard of living and a modicum of economic activity for all their citizens, a sense of participation from all groups in society, and restraint on the concentration of economic power so that it does not become an instrument of cultural and political exploitation. On the psychological plane the developing countries desire to shake off the hurt and humiliation of their colonial past. Both these desires are interlinked; and both must be realised.

In this context, Singh's emphasis on self-reliance and self-sufficiency takes on a special meaning. The developing countries need to isolate themselves from western science and technology, perhaps even more so from the western 'development consultants'.
The principle of self-reliance and self-sufficiency requires making do with what one has and developing one's indigenous resources with one's own skills and effort. The developing countries must develop their own, albeit humble, less pretentious, style of science and technology. The emphasis should be on indigenous development stemming from rural cultures and the need for encouraging cultural authenticity. The traditional cultures must be protected from the onslaught of western patterns of consumption and those consumer goods that represent the omnipotence of technology (including 'Space 1999' and Bionic Woman!).

The 'republic of science' with its insistence on the international and universal character of scientific activity, the all-encompassing emphasis on the objectivity of science and its quest for truth, and the rejection of any type of imposition on the selection of research topic, has no role to play here. It is this very republic that in the name of objectivity and truth perpetuates the dependency trap.

Developing countries should reject all offers of western technological assistance. The acceptance of this aid acts against their two basic desires mentioned above. It encourages elitism and concentrates economic power in fewer and fewer hands. It generates a sense of indignity. It enforces western patterns of development, increases dependency, and enhances the prestige of western science and technology. Because foreign technology has been readily accessible in the past, there has been little pressure on the domestic scientific community to provide viable alternatives. The resulting inactivity has reduced the domestic scientific communities to mediocrity, and alienated the creative.

The practice of sending students for higher education to the West has perpetuated the technological dominance of the West. The 'been to's are misfits; they are unable to meet the indigenous requirements on the one hand, and generate a sense of inferiority in the local scientists on the other. Their hopes, aspirations and desires go against the dictates of self-reliance and self-sufficiency. They can only retain their position by identifying themselves with the western scientific community. One finds them zealously defending their (western) research interests and universalism of science. The national papers for UNCSTD will largely be prepared by such individuals; and, as such, they are hardly likely to be in the national self-interest.

The Science Policy Research Unit at the University of Sussex has shown that less than $1 \%$ of the total research effort of the developed countries has any significance for the developing world. Under such circumstances, involvement in western scientific communication systems only distracts the scientists in the developing countries from the more pressing local issues. Hence there is a need for the developing countries to evolve their own network of scientific communications. Visiting scientists should go to centres of scientific activity in another developing country, rather than to the centres of the West.

Where some developed countries (such as Italy) are experiencing an enforced de-development, and others are hovering from crisis to crisis, a little isolation from western science and technology may not be a bad thing for the developing countries. Even the smaller and weaker amongst them which see technological and scientific aid as a stark necessity must feel a sense of discomfort at making demands from a position of weakness.

The equation, however, must be balanced. Both selfreliance and dignity begin from the self. The developing countries must take a searching look at themselves, develop their own capabilities and meet their own needs.

Meanwhile, if UNCSTD brings positive results, let us all share the glad tidings! 